\title{
PEMBERDAYAAN MAHASISWA DENGAN MASYARAKAT DESA MANSALONG DAN DESA TANJUNG HULU KABUPATEN NUNUKAN MELALUI OPTIMALISASI POTENSI LOKAL DENGAN PENDEKATAN REVOLUSI MENTAL DALAM MEWUJUDKAN DESA BERSIH DAN MANDIRI
}

\section{Empowerment Of Students With The Mansalong Village Community And Tanjung Hulu Village, Nunukan District Through Optimization Of Local Potentials With Mental Revolution Approach To Realize Clean And Independent Village}

\author{
Hendy Lesman ${ }^{1 *}$, Mohammad Wahyu Agang ${ }^{2}$ \\ ${ }^{I^{*} J u r u s a n}$ Keperawatan, Fakultas Ilmu Kesehatan, Universitas Borneo Tarakan \\ ${ }^{2}$ Jurusan Agribisnis, Fakultas Pertanian, Universitas Borneo Tarakan \\ Jl. Amal Lama No.1, Tarakan \\ *e-mail Korespodensi: hendylesmana2@gmail.com
}

\begin{abstract}
ABSTRAK
Desa Mansalong \& Desa Tanjung Hulu adalah mitra dan semangat gerakan Indonesia melayani PKM Revolusi Mental Universitas Borneo Tarakan Menuju kesadaran dan kepedulian baik masyarakat maupun pemerintahan desa terhadap kebersihan dan kesehatan, serta gerakan Indonesia mandiri PKM Revolusi Mental Universitas Borneo Tarakan meningkatkan tingkat kesadaran kemandirian masyarakat melalui menemukan potensi lokal sebagai badan usaha milik desa. Kurangnya kesadaran pelayanan publik dan kemandirian usaha di Wilayah Kecamatan Lumbis, Kabupaten Nunukan, solusi yang dilakukan dengan melaksanakan program Revolusi Mental Melalui gerakan Indonesia Bersih dan Gerakan Indonesia Mandiri.Untuk mewujudkan pemecahan permasalahan tersebut diperlukan suatu penataan dengan gerakan aksi nyata Bersih. Mandiri berbasis Revolusi Mental. Program Kemitraan Masyarakat berbasis Revolusi mental Melatih masyarakat dan memberikan pembekalan ilmu pengetahuan untuk mengembangkan potensi yang dimiliki, baik potensi alam maupun potensi yang ada di dalam diri masyarakat. Melalui gerakan Indonesia Bersih Program Kemitraan Masyarakat Revolusi Mental Universitas Borneo Tarakan Menuju kesadaran dan kepedulian baik masyarakat maupun pemerintahan desa terhadap kebersihan lingkungan. Sedangkan gerakan Indonesia mandiri terfokus pada pada pemanfaatan potensi sumber daya alam daerah tertinggal, Mendukung dan mendorong kewirausahaan serta ekonomi kreatif memberdaakan potensi lokal, dan Melakukan pengembangan teknologi tepat guna untuk mendorong Usaha ekonomi kreatif.
\end{abstract}

Kata Kunci: Pemberdayaan Masyarakat, Kemitraan, Revolusi Mental

\section{ABSTRACT}

Mansalong Village \& Tanjung Hulu Village are partners and the spirit of the Indonesian movement serving the PKM Borneo Tarakan University Mental Revolution Towards awareness and concern for both the community and village government towards hygiene and health, and the independent Indonesian movement PKM Borneo Tarakan Mental Revolution increases the level of awareness of community independence through finding local potential as a village-owned business entity. Lack of awareness of public service and business independence in the Lumbis Subdistrict Area, Nunukan Regency, a solution that was carried out by implementing the Mental Revolution program through the Clean Indonesia movement and the Independent Indonesia Movement. To realize the solution to these problems, a structuring with a real Clean, Independent action based on Mental Revolution is needed. Mental Revolution-based Community Partnership Program Train the community and provide knowledge training to develop their potential, both natural potential and the potential that exists within the community. Through the Clean Indonesia movement Partnership Program Borneo Tarakan University Mental Revolution Community Towards awareness and concern for both the community and the village government towards environmental cleanliness. Whereas the independent Indonesia movement is focused on the utilization of the potential of underdeveloped natural resources, supporting and encouraging entrepreneurship and the creative economy empowering local potential, and developing appropriate technologies to encourage creative economic enterprises.

Keywords: Community Empowerment, Partnership, Mental Revolution

Hendy L., M. Wahyu A., PEMBERDAYAAN MAHASISWA...

Available at http:// jurnal.borneo.ac.id/index.php/jpmb 


\section{PENDAHULUAN}

Desa Tanjung Hulu merupakan salah satu desa yang terdapat di Kecamatan Lumbis. Desa Tanjung Hulu memiliki luas $692 \mathrm{Ha}$, dengan jumlah penduduk 298 orang dengan uraian sebagai berikut; lakilaki 148 orang dan perempuan 150 orang. Jumlah kepala keluarga 78 kepala keluarga. Mayoritas penduduk Desa Tanjung Hulu berprofesi sebagai peratni (54 orang) dan PNS sebanyak 1 orang. Pendidikan masyarakat paling banyak Tamatan SD yakni sebanyak 46 orang, kemudian yang tamat SLTA sebanyak 32 orang dan tidak lulus SD sebanyak 32 orang.

Desa Tanjung Hulu terletak pada ketinggian 50 - 300 mdpl. Secara topografi, wilayah Desa Tanjung Hulu berada pada perbukitan, pegunungan dan dataran rendah. Perbukitan terletak pada sebelah barat permukiman, dataran rendah terletak pada daerah sekitar Sungai Sembakung dan permukiman, sedangkan pegunungan berada pada batas antara Desa Tanjung Hulu dengan Kabupaten Malinau dan Desa Sapuyan.

Keadaan alam di desa Tanjung Hulu juga sangat melimpah yaitu bisa dilihat dari potensi desa terdiri atas : kelapa sawit, singkong, padi gunung, buah-buahan, kopi, kakao, merica, jagung, kacang-kacangan, tanaman sayur-sayuran, perikanan air tawar, peternakan, hasil hutan dan kerajinan lokal. Permasalahan yang di temui di Desa Tanjung Hulu adalah : Kurangnya pengetahuan masyarakat tentang kewirausahaan daerah.

Kurangnya kesadaran masyarakat akan pentingnya literasi/membaca Kurangnya kesadaran masyarakat akan pentingnya kesehatan lingkungan. Untuk mewujudkan pemecahan permasalahan tersebut diperlukan suatu penataan dengan gerakan aksi nyata Bersih, Tertib dan Mandiri berbasis Revolusi Mental.

Dengan melalui keterpaduan tridarma perguruan tinggi melalui pemberdayaan Kermitraan masyarakat berbasis revolusi mental yang memiliki nilai integritas, etos kerja dan gotong royong menjadi alasan kami untuk mengembalikan semangat pembangunan Kabupaten Nunukan dengan menjadi Desa Bersih, Maju, dan Mandiri.

Berdasarkan hasil penelusuran awal yang dilakukan oleh penulis terdapat beberapa permasalahan yang ditemukan di desa mitra, antara lain : Kurang pemahaman masyarakat terhadap pemanfaat sumberdaya lokal yang dapat meningkatkan pendapatan keluarga melalui pendekatan kewirausahaan keluarga.

Kurangnya kesadaran masyarakat akan pentingnya kebersihan lingkungan dimana masyarakat masih membuang sampah di sungai atau di sembarang tempat. Tidak terdapat taman bacaan masyarakat yang menjadi tempat masyarakat menumbuhkan kesadaran pentingnya membaca buku guna peningkatan pengetahuan masyarakat desa. Masih banyak terdapat penyalahgunaan obat-obatan terlarang dikalangan generasi muda. Masih banyak terdapat pasangan suami istri dengan umur yang masih dibawah anjuran dari pemerintah (pernikahan dini).

\section{METODE}

Metode Pelaksanaan kegiatan Program Adapun materi yang diberikan dalam sosialisasi PKM adalah tentang sosial budaya, pemberdayaan Pendidikan, Pemberdayaan Kesehatan Masyarakat, wawasan revolusi mental, bidang administrasi baik administrasi negara maupun hukum administrasi dan teknik. Survei/Observasi ke lokasi, mitra dan 
kelompok masyarakat yang dijadikan sasaran PKM.yaitu di Kecamatan Lumbis dengan fokus pada Desa Mansalong dan Desa Tanjung Hulu.

Kegiatan akan dilaksanakan menggunakan metode partisipatoris. Jadi, pelaksanaan program dilakukan dengan melibatkan masyarakat setempat dan mahasiswa Kuliah Kerja Nyata sebagai fasilitator. Untuk itu, diperlukan pendampingan dalam setiap kegiatan agar dapat diketahui dinamika dari kegiata tersebut sehingga dapat mewujudkan tujuan pemberdayaan. Adapun kegiatan yang di rancang adalah: (1) Bimbingan teknis/Pendampingan/Penyuluhan berupa aktivitas kegiatan usaha ekonomi keluarga oleh mahasiswa bersama masyarakat; (2) Aktivitas pendukung lainnya dalam rangka mengembangkan Kesadaran kebersihan, kesehatan lingkungan serta nasionalisme dengan program Gerakan Indonesia melayani dan Gerakan Indonesia Mandiri. (3) aktivitas dalam meningkatkan perilaku kesadaran masyarakat akan pentingnya belajar/membaca.

\section{HASIL DAN PEMBAHASAN}

Kegiatan revolusi mental gerakan indonesia bersih yang dilaksanakan di Desa Mansalong dan Desa Tanjung Hulu meliputi ; Program penanggulangan sampah masyarakat. Melalui pengelolaan sampah masyarakat dengan baik dan benar. Hasil kegiatan berupa telah tercipta sistem pengangkutan sampah rumah tangga mulai dari pengumpulan, distribusi sampah, pembiayaan hingga pembuangan dan pengelolaan sampah tersebut. Pembuatan Tong sampah dan Pembuatan plang himbauan berupa "dilarangan buang sampah di sungai”.

Kerjabakti di Fasilitas Umum, selain itu pula meningkatkan semangat gotong royong dari masyarakat. Hasil kegiatan berupa Kerja bakti di tempat pemakaman Umum, kerja bakti di lapangan bola guna persiapan lomba dalam rangka memperingati hari kemerdekaan Indonesia, Kerja bakti di Kantor Desa Mansalong dan Desa Tanjung Hulu Senam Sehat dan Joging Program ini bertujuan untuk meningkatkan kebugaran dan kesehatan dari masyarakat serta menumbuhkan budaya olah raga bagi masyarakat.

Kegiatan ini berupa senam sehat bersama di SMAN 1 Lumbis, senam sehat bersama di SMPN 1 Lumbis, senam sehat bersama di SDN 009 Lumbis dan melatih senam anak-anak SDN 009 Lumbis dan SDN 006 Tanjung Hulu serta joging pagi bersama anak-anak Sekolah Dasar Penyuluhan Kesehatan Program ini bertujuan untuk meningkatkan pengetahuan masyarakat mengenai kesehatan meliputi; pentingnya imunisasi, Perilaku Bersih Dan Sehat (PHBS), Penanggulangan sampah, Bahaya Narkoba dan Pernikahan Dini.

Melalui gerakan Indonesia Bersih KKNRevolusi Mental Universitas Borneo Tarakan Menuju kesadaran dan kepedulian baik masyarakat maupun pemerintahan desa terhadap kebersihan lingkungan dan perilaku hidup bersih dan sehat.

Aksi Revolusi Mental Gerakan Indonesia Mandiri Gerakan Indonesia Mandiri (GIMa) adalah gerakan para Penyelenggara Negara dan masyarakat untuk mendorong budaya kreatif, inovatif, dan beretos kerja tinggi untuk meningkatkan produktivitas dan daya saing bangsa.

Gerakan ini akan mendorong terwujudnya kemandirian dalam berbagai sector kehidupan, seperti pertumbuhan kewirausahaan dan ekonomi kreatif, peningkatan UMKM dan koperasi, 
peningkatan apresiasi seni, kreativitas karya budaya dan warisan budaya. Peningkatan kemandirian terutama nilai etos kerja merupakan faktor strategis dalam menghadapi persaingan regional dan global. Gerakan ini dilakukan oleh para penyelenggara negara dan masyarakat yang saling bersinergi untuk mewujudkan kemandirian bangsa di berbagai sektor kehidupan. Gerakan Indonesia Mandiri, adalah gerakan untuk mewujudkan perilaku kreatif, inovatif, dan beretos kerja tinggi agar mewujudkan kemandirian dibidang pangan, energi, dan teknologi dalam menghadapi persaingan regional dan global. Kegiatan Aksi revolusi mental gerakan indonesia mandiri di Desa Mansalong dan Desa Tanjung Hulu adalah; Pendirian Taman Bacaan Masyarakat. Program ini bertujuan untuk memfasilitasi warga untuk menumbuhkan minat membaca dan membudayakan minat baca bagi warga Desa Mansalong dan Desa Tanjung Hulu. Pelatihan kewirausahaan masyarakat.

Program ini bertujuan untuk meningkatkan pengetahuan masyarakat akan kewirausahaan masyarakat sehingga dapat meningkatkan perekonomian keluarga dan masyarakat. Hasil kegiatan ini berupa pelatihan kewirausahaan masyarakat dengan memanfaatkan bahan lokal ada ada di kedua desa. Pelatihan tentang Aquaponik dan MOL. Tujuan dari kegiatan ini adalah meningkatkan pengetahuan dan keterampilan masyarakat mengenai tehnik pembuatan aquaponik dan MOL sehingga masyarakat dapat mengembangkan di pekarangan guna meningkatkan ekonomi masyarakat dan meningkatkan ketahanan pangan keluarga. Hasil kegiatan berupa pelatihan tentang aquaponik dan MOL.

Penyuluhan gerakan revolusi mental. Kegiatan ini bertujuan meningkatkan pengetahuan masyarakat mengenai pentingnya gerakan revolusi mental sehingga mempercepat tujuan negara menjadi negara yang mandiri, berdaulat dan berkeadilan. Hasil kegiatan ini berupa penyuluhan gerakan revolusi mental kepada kedua desa yakni Desa Mansalong dan Desa Tanjung Hulu.

Gerakan indonesia melayani difokuskan pada peningkatan kapasitas sumberdaya manusia aparatur sipil negara (pelayan masyarakat) dalam penyempurnaan sistem manajemen kerja dan peningkatan perilaku pelayanan publik yang cepat, transparan, akuntabel dan responsif.

Kegiatan aksi revolusi mental gerakan indonesia melayani di Desa Mansalong dan Desa Tanjung Hulu adalah; Pembuatan dan pemasangan nomor rumah Tujuan dari kegiatan ini adalah memberikan identitas rumah sehingga mudah mengenali dan mendeteksi rumah yang ada di Desa Mansalong dan Desa Tanjung Hulu. Hasil kegiatan berupa pembuatan dan pemasangan nomor rumah di teras rumah pada kedua desa.

Pembuatan dan pemasangan plang Rukun Tetangga (RT) Tujuan dari kegiatan ini adalah agar masyarakat luar mengetahui rumah dan kewajiban lapor ke ketua RT bagi masyarakat luar yang berkunjung ke desa tersebut. Hasil kegiatan berupa pembuatan dan pemasangan plang Rukun tetangga (RT) di rumah ketua RT. Sosialisasi ciri keaslian rupiah emisi 2016. Kegiatan ini bertujuan untuk meningkatkan pemahaman masyarakat tentang ciri keaslian rupiah emisi tahun 2016.

Hasil kegiatan berupa ; penyuluhan mengenai ciri keaslian mata uang rupian emisi tahun 2016 kepada masyarakat di kedua desa. Melayani bimbingan belajar bagi anak sekolah dasar dan sekolah menengah pertama. Program ini bertujuan untuk memberikan peningkatan 
pengetahuan dan pemahaman siswa setelah mereka belajar di sekolah formal.

Hasil kegiatan telah dilaksanakan bimbingan belajar bagi anak sekolah SD dan anak sekolah SMP di kedua desa. Pembuatan maket miniatur desa dan profil desa. Kegiatan ini memiliki tujuan mempermudah masyarakat dan orang luar dari desa untuk mengetahui data statistik mengenai desa Mansalong dan Desa Tanjung Hulu. Hasil kegiatan berupa pembuatan maket miniatur desa dan profil desa.

\section{PENUTUP}

Kegiatan Program Kemitraan Masyarakat berbasis Revolusi mental dengan gerakan Indonesia Bersih, Gerakan Indonesia Mandiri dan Gerakan indonesia melayani di Desa Mansalong dan Desa Tanjung Hulu Kecamatan Lumbis
Kabupaten Nunukan berjalan dengan baik dan mendapat dukungan penuh dari Camat Lumbis, Kepala Desa Mansalong dan Kepala Desa Tanjung Hulu, tokoh masyarakat serta seluruh masyarakat.

\section{DAFTAR RUJUKAN}

Badan Pusat Statistik Kabupaten Nunukan. 2018. Kabupaten Nunukan Dalam Angka 2018. BPS Kabupaten Nunukan.

Instruksi Presiden Republik Indonesia Nomor 12 Tahun 2016. Gerakan Revolusi Mental.

$\begin{array}{crr}\text { Kementrian } & \text { Koordinator } & \text { Bidang } \\ \text { Pembangunan Manusia Dan } & \text { Debudayaan. 2015. Sosialisasi } \\ \text { Kebakan Nasional } & \text { Revolusi } \\ \text { Gerakan } & \text { Mental. Disampaikan di Jakarta } \\ \text { Tanggal 21 } & \text { Agustus } 2015 .\end{array}$


